San Jose State University

SJSU ScholarWorks

Master's Projects

Master's Theses and Graduate Research

$5-17-2000$

\title{
Evaluation of the Effectiveness of a Urinary Continence Program with Urinary Incontinent Rehabilitation Patients
}

Pat Emmons

San Jose State University

Follow this and additional works at: https://scholarworks.sjsu.edu/etd_projects

Part of the Other Nursing Commons

\section{Recommended Citation}

Emmons, Pat, "Evaluation of the Effectiveness of a Urinary Continence Program with Urinary Incontinent Rehabilitation Patients" (2000). Master's Projects. 848.

DOI: https://doi.org/10.31979/etd.q799-tnvq

https://scholarworks.sjsu.edu/etd_projects/848

This Master's Project is brought to you for free and open access by the Master's Theses and Graduate Research at SJSU ScholarWorks. It has been accepted for inclusion in Master's Projects by an authorized administrator of SJSU ScholarWorks. For more information, please contact scholarworks@sjsu.edu. 


\section{SAN JOSE STATE UNIVERSITY \\ SCHOOL OF NURSING}

\section{MASTER'S PROGRAM PROJECT OPTION (PLAN B) PROJECT SIGNATURE FORM}

$\begin{array}{ll}\text { STUDENT NAME } & \text { PAT EMMONS } \\ \text { SEMESTER ENROLLED } & S 2000\end{array}$

TITLE OF PROJECT Evaluaturn of the Effecluenes

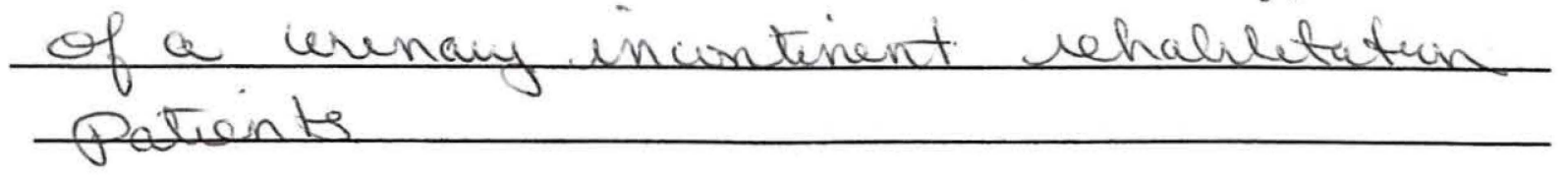

NAME OF JOURNAL WOCN

The project and manuscript have been successfully completed and meet the standards of the School of Nursing at San Jose State University. The project demonstrates the application of professional knowledge, clinical expertise, and scholarly thinking. An abstract of the project and two copies of the manuscript are attached.
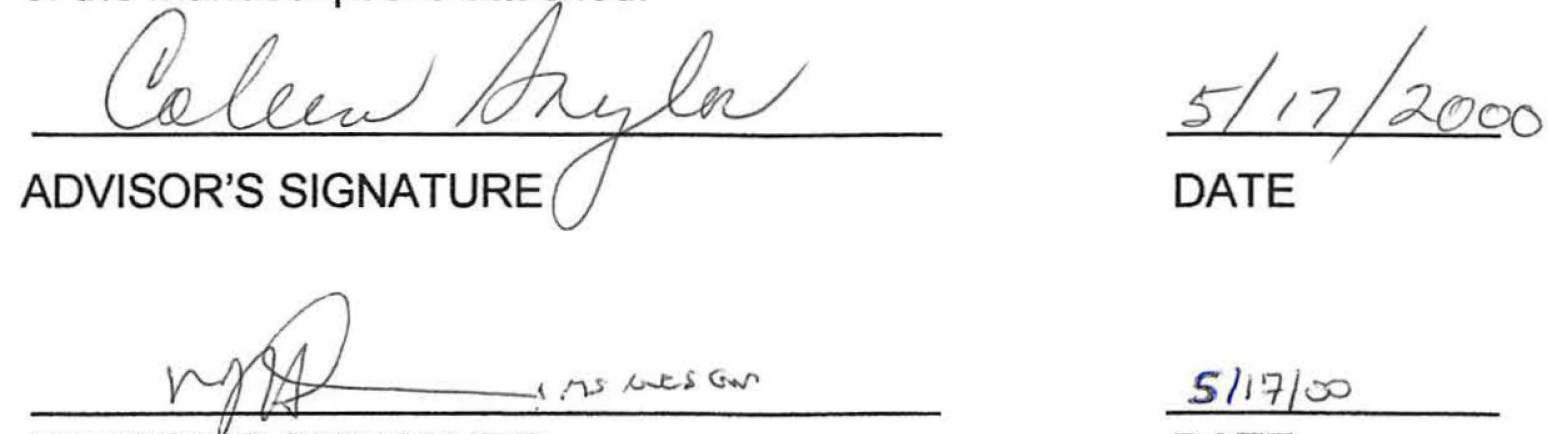

ADVISOR'S SIGNATURE

$5 / 17100$

DATE

Please submit this form to the Graduate Coordinator. Attach abstract, two copies of the manuscript, and documentation of submission to the journal (i.e., postal receipt). 
Evaluation of Urinary Incontinence Program

\begin{abstract}
This study used a quasi-experimental design to evaluate the outcomes of a continence program in a rehabilitation center with patients receiving therapies $(\underline{N}=12)$ and to evaluate the knowledge and attitudes of the rehabilitation staff $(\underline{N}=27)$ before and after reviewing a teaching module about urinary incontinence. Roy's adaptation theory was used as the conceptual framework for this research project. The tools used for data collection were: the Functional Independence Measure (FIM), daily 24 hour incontinence logs, pre/post true and false knowledge tests and pre/post staff attitude questionnaires. Eleven of the 12 patients admitted to the program had improved FIM scores and had gained urinary continence by discharge. Although attitudes did not change, staff knowledge improved by almost 1 test question between pre/posttests. There was a statistically significant difference $(\mathrm{p}=.008)$ between the pre/posttest mean scores on the true/false test with the patient care intervention questions. The Roy adaptation model integrates well into a rehabilitation unit's continence program. Scheduled voiding as a behavioral therapy used with rehabilitation patients is a successful treatment modality in helping gain urinary continence.
\end{abstract}


Evaluation of Urinary Incontinence Program

EVALUATION OF THE EFFECTIVENESS OF A URINARY CONTINENCE PROGRAM
WITH URINARY INCONTINENT REHABILITATTION PATIENTS

$$
\text { Original Article }
$$

By Pat Emmons M.S., R.N.E.T., and Coleen Saylor, Ph.D., R.N. May 2000

Corresponding Author:

Pat Emmons M.S., R.N.E.T., Administrative Coordinator, Dominican Hospital,

Coleen Saylor, Ph.D., Professor, San Jose State University, School of Nursing One Washington Square, San Jose, CA. 951920057 
Evaluation of Urinary Incontinence Program

\begin{abstract}
This study used a quasi-experimental design to evaluate the outcomes of a continence program in a rehabilitation center with patients receiving therapies $(\underline{\mathrm{N}}=12)$ and to evaluate the knowledge and attitudes of the rehabilitation staff $(\underline{N}=27)$ before and after reviewing a teaching module about urinary incontinence. Roy's adaptation theory was used as the conceptual framework for this research project. The tools used for data collection were: the Functional Independence Measure (FIM), daily 24 hour incontinence logs, pre/post true and false knowledge tests and pre/post staff attitude questionnaires. Eleven of the 12 patients admitted to the program had improved FIM scores and had gained urinary continence by discharge. Although attitudes did not change, staff knowledge improved by almost 1 test question between pre/posttests. There was a statistically significant difference $(\mathrm{p}=.008)$ between the pre/posttest mean scores on the true/false test with the patient care intervention questions. The Roy adaptation model integrates well into a rehabilitation unit's continence program. Scheduled voiding as a behavioral therapy used with rehabilitation patients is a successful treatment modality in helping gain urinary continence.
\end{abstract}


Evaluation of Urinary Incontinence Program

\section{Background}

Urinary incontinence is defined by the Agency of Health Care Policy and Research (U.S. Dept. of Health \& Human Sciences, 1996) to be the "involuntary loss of urine sufficient to be a problem" (p. 130). Although urinary incontinence is thought by some to be a normal process of aging, researchers believe certain biological changes predispose the elderly to incontinence: (a) restricted mobility, (b) altered vision, (c) altered mentation, (d) lack of motivation, (e) medications, (f) presence of urinary tract infection, (g) number of pregnancies, (h) diminished bladder capacity, (i) detrusor instability, (j) decreased dexterity, and (k) certain medical conditions which predispose to incontinence (Burgio \& Goode, 1997; Ouslander \& Schnelle, 1995; Penn, Lekan-Rutledge, Joers, Stolley, \& Amhof, 1996; Resnick, 1995; Tinetti, Inouye, Gill, \& Doucette, 1995).

Urinary incontinence in the elderly is a costly health care issue that makes an impact on physical and emotional well being. Wagner and $\mathrm{Hu}(1998)$ stated that the financial cost of caring for incontinent elders "noninstitutionalized and institutionalized ages 65 years and older was approximately 31.76 and 1.89 million respectively" (p. 356). Urinary incontinence is a disabling disorder which is associated with morbidity, and frequently it can lead to pressure ulcers, urinary tract infections, falls, inappropriate catherization, social isolation, depression, and unnecessary institutionalization (Rousseau \& Fuentevilla-Clifton, 1992).

A key issue making data collection regarding urinary incontinence difficult is that it is not defined as an illness by the National Center for Health (Hu, 1990). "Urinary incontinence affects approximately 13 million Americans or about 10-35 percent of adults and at least half of the 1.5 
Evaluation of Urinary Incontinence Program

million nursing home residents" (Medical Outcomes \& Guidelines Sourcebook, 1997, p. 128). Wagner and Hu (1998) stated 7.4 million Americans over the age of 65 have urinary incontinence. Cummings, Holt, van der Sloot, Moore, and Griffiths (1995) measured the costs of managing urinary incontinence in long-term care facilities and identified more than $50 \%$ of the 48 residents with urinary incontinence. "For noninstituitionalized persons older than 60 years of age, prevalence ranges from 15 to 35 percent, with women having twice the prevalence of men. Survey data from caregivers of the elderly show that approximately 53 percent of the homebound elderly are incontinent" (Medical Outcomes \& Guidelines Sourcebook, 1997, p. 128).

Although urinary incontinence affects nearly 10 million American men and women, it is estimated only one in five will come to the attention of physicians or health care workers (Appel \& Baum, 1992). Many elderly with urinary incontinence tend to hide their incontinence problem from peers and health care workers because of shame and embarrassment (Mitteness, 1990). Some elderly in their hesitancy to discuss urinary incontinence, may. remain ignorant of appropriate treatment modalities and interventions preferring to use incontinence pads and limit social activities to manage urinary incontinence (Brazier \& Kramer, 1999).

The Agency of Health Care Policy and Research (U.S. Dept. of Health \& Human Services, 1996) defines six types of urinary incontinence:

1. Urge incontinence is the involuntary loss of urine associated with an abrupt and strong desire to void. 


\section{Evaluation of Urinary Incontinence Program}

2. Stress incontinence is the involuntary loss of urine from the urethra during physical exertion such as during coughing.

3. Mixed incontinence is the combination of urge and stress urinary incontinence.

4. Overflow incontinence is the involuntary loss of urine associated with the over distension of the bladder.

5. Functional incontinence is the involuntary urinary loss of urine associated with factors outside the lower urinary tract such as inability to toilet because of impairment of cognitive and/or physical functioning, psychological unwillingness, or environmental barriers.

6. Reflux incontinence is the involuntary loss of urine occurring without warning or sensory awareness such as in paraplegics and some patients without overt neurologic dysfunction.

The three major methods of treating all types of urinary incontinence are (a) behavioral, (b) pharmacological, and (c) surgical (Messick \& Powe, 1997). The 1996 A.H.C.P.R. Guidelines on Urinary Incontinence made the recommendation, "to use the least invasive treatment with the fewest potential adverse complications" (p. 31) Interventions for urinary incontinence would begin with behavioral techniques. The Guidelines on Urinary Incontinence include (a) toileting assistance by scheduled or routine toileting, habit training, and prompted voiding, and (b) bladder retraining which includes an educational program with systematic scheduled voiding delay and positive reinforcement. The third major method is (c) pelvic muscle rehabilitation which includes pelvic muscle exercise augmented by biofeedback, 


\section{Evaluation of Urinary Incontinence Program}

vaginal weight training, and pelvic floor electrical stimulation. (U.S. Dept. of Health \& Human Services, 1996).

\section{Purpose of Study}

The purpose of this research study was to evaluate the outcomes of a continence program in a rehabilitation center with patients receiving therapies, and to evaluate the knowledge and attitudes of the rehabilitation staff before and after reviewing a teaching module about urinary incontinence. The patient population had urge or mixed incontinence and were predominantly recovering stroke patients. A scheduled voiding program was utilized as the method of behavioral therapy to treat their urinary incontinence. Although stroke patients are considered to have urge incontinence, it is not uncommon for patients, especially women, to present with mixed incontinence (U.S. Dept. of Health \& Human Services, 1996). This research topic is both timely and valuable because of the prevalence of urinary incontinence in the elderly population, the impact of incontinence on quality of life, and the associated health care costs.

\section{Literature Review}

This literature review will focus primarily on research studies dealing with behavioral therapy modalities demonstrating efficacy for decreasing urinary incontinence. Linn, Best, and Holzapfel (1995) initiated a "prompted voiding" program for a male population at an intermediate care unit, Veteran Administration Medical Center, Murfreesboro, Tennessee. After the behavioral therapy the male patients engaged in toileting practices more often and were more continent. However, after 3 months these patients had regressed to baseline incontinence levels which suggested that maintenance of "prompted voiding" cues were needed. 
Evaluation of Urinary Incontinence Program

Older women have been the focus of several programs utilizing behavioral therapy interventions to reduce urinary incontinence. For example, Wyman, Fantl, McClish, Bump, and the Continence Program for Women Research Group (1998) compared the efficacy of behavioral interventions in the management of 204 out patient women with urinary incontinence. These women were randomly assigned into one of three groups: (a) bladder training, (b) pelvic muscle exercises with biofeedback-assisted instruction, and (c) a combination therapy using both interventions. The 12-week intervention program utilized 6 weeks of office visits and 6 weeks of mail/telephone contacts, and there was a 3 month follow-up. The incontinent cure rate was higher in the combined therapy group ( $31 \%$ ) compared to the bladder training group (18\%) and the pelvic exercise group (13\%). There was a reduction of incontinent episodes by $50 \%$ or greater among $70 \%$ of the participants in the combined therapy group, $56 \%$ for the pelvic muscle exercise group, and $51 \%$ for the bladder training group. At 6 weeks, participants in the bladder-training group had the lowest weekly number of incontinent episodes. The combined therapy group reported greater improvement and greater patient satisfaction at 3 months after treatment as indicated by patient response and the incontinence severity indexes.

Fantl et al. (1991) studied 123 women, 55 years and older, who were urodynamically categorized into detrusor instability or urethral sphincter incompetence. These women were randomly divided into a control or treatment group. The treatment group underwent a 6 week bladder-training program which included 6 weekly clinic visits where clinicians reviewed daily treatment logs. Although the older women in this study presented with more severe symptoms, age did not affect the outcomes. At the end of the study, $12 \%$ of the treated group reported no 


\section{Evaluation of Urinary Incontinence Program}

incontinent episodes and 75\% reported a 50\% reduction of incontinent episodes. In Fantl's (1998) literature review article only 11 large sample size bladder-training intervention studies in community dwelling women with urinary incontinence were found. His 1991 study was the most recent study and was one of three randomized studies.

Publicover and Bear (1997) evaluated a bladder-training program for 16 urinary incontinent community dwelling older women. The bladder-training program consisted of (a) bladder diaries, (b) mandatory voiding schedules, and (c) weekly telephone calls. After 4 weeks, 11 of the women were continent and 2 additional women had a $50 \%$ reduction of incontinence.

Another randomized research study by Burgio et al. (1998) compared behavioral therapies against drug therapy for urge incontinence in older women. One hundred ninety seven women over 55 years of age were randomized into three groups: (a) biofeedback-assisted behavior treatment, (b) standard drug treatment, and (c) a placebo control group treatment. All the women were seen every 2 weeks for 8 weeks in a clinic setting. Each session was designed for specific intervention; for example, one session taught the client not to rush to the toilet when the urge to urinate arose, but rather they were to pause, sit, relax, and contract pelvic muscles. Upon completion of the therapy, the behavioral therapy group accomplished between a $50 \%$ and $75 \%$ reduction in urinary incontinent episodes. The women in the behavioral therapy group perceived the highest improvement and satisfaction with the bladder-training program.

Weinberger, Goodman, and Carnes (1999) completed a long-term study with 81 community dwelling women over the age of 60 with urinary incontinence. The treatment modalities included: (a) pelvic muscle exercises, (b) bladder retraining, (c) caffeine restriction, 
Evaluation of Urinary Incontinence Program

(d) estrogen replacement, (e) biofeedback, (f) functional electrical stimulation, and (g) pharmacology therapy. Treatment modalities were selected based upon individual clinical symptoms, and according to urological and/or gynecological diseases. The number of clinic visits were individualized and continued until continence was accomplished. A survey was sent to all participants 1 year after their last clinic visit. Of the surveys returned (53/81), $43 \%$ of the patients stated that incontinence was not a problem or was a mild problem, however $33 \%$ reported moderate incontinence. Patients with more severe incontinence reported poorer health and more physical limitations. Participants ranked pelvic muscle exercises, bladder retraining, and caffeine restriction as being the preferred treatments most effective in reducing their incontinence. Delayed voiding and pelvic muscle exercises were more effective than pharmacological therapy.

Although behavioral interventions, especially bladder training, have been successful in dealing with urinary incontinence, only a limited number of urinary incontinence studies have been done utilizing behavioral therapies with stroke patients in rehabilitation units even though urge incontinence and/or a combination of stress and urge incontinence are usually present in this patient population. Some of the studies done in rehabilitation units looked at predictors or factors which influenced regaining urinary continence, or predictors for institutionalization post discharge from the unit (Glasser, Zorowitz, \& Linsenmeyer, 1997; Kamouchi et al. 1995; Owen, Getz, \& Bulla, 1995; Ween, Alexander, D’Espositio, \& Roberts, 1996). In addition to improving client outcomes, health care providers can improve knowledge and attitudes about urinary incontinence, which may in time enhance the effectiveness of urinary incontinence programs. 


\section{Evaluation of Urinary Incontinence Program}

Yu and Kaltreider (1987) utilized the Incontinence Stress Questionnaire-Staff Reaction (ISQ-SR) to survey 156 nursing staff in nursing homes and a country home. Forty-eight percent of the nursing staff stated that they were comfortable working with urinary incontinent patients, but some of the participants ( $38-43 \%)$ were "depressed" about their work, especially the extra work, associated with incontinent patients. Another $45 \%$ stated some of the time they disliked changing wet clothes and linen. This survey identified the psychological stress associated with urinary incontinence care by health care workers in the nursing home setting.

Cheater (1991) surveyed 382 British nursing staff using a Likert questionnaire to elicit staff attitudes regarding continence management. The nursing staff generally had limited information in the treatment options for urinary incontinence, and a limited number (24\%) thought a catheter in the early stages of stroke should be utilized. About $11 \%$ of the respondents thought urinary incontinence was a natural process of aging. Another $28 \%$ of the nursing staff thought urinary incontinence in an elderly person would not be as distressing as incontinence for a younger person. Laziness was cited by $16 \%$ of the nursing staff as the reason for urinary incontinence. Although the nursing staff recognized the need for rehabilitation care with incontinence patients, they still had many misconceptions regarding the care of incontinent patients. Freundl and Dugan (1992) demonstrated that long-term care providers have limited education regarding urinary incontinence. They surveyed 16 agencies utilizing an Incontinence Stress Questionnaire. Three hundred and forty six nursing personnel (92 RNs, 62 LVNs, 191 NAs) completed the questionnaire, representing approximately $28 \%$ of the total employee population, and it was demonstrated that there was limited educational knowledge of 
Evaluation of Urinary Incontinence Program

urinary incontinence and limited ability by the nursing staff to apply current nursing research to specific clinical situations.

Hancock, Bender, Dayhoff, and Nyhuis (1996) surveyed 150 nursing staff in an acute hospital setting to assess the knowledge and attitudes of nursing staff caring for urge and stress incontinent patients. Vignettes were used to describe a patient with stress incontinence and a patient with urge incontinence. Urge incontinence was seen by the nursing staff as a temporary situation whereas stress incontinence was perceived to continue after the patient was discharged from the hospital. Respondents seemed to be more positive regarding the intervention outcomes of urge incontinence. The nursing staff believed patients were not likely to expect or ask for assistance with urinary incontinence. These researchers suggested that the nursing staff needed additional education regarding urinary incontinence.

Connor and Kooker (1996) surveyed 208 nursing staff in an acute care hospital to evaluate nursing staffs' perceptions of assignments with several urinary incontinent patients. The study included attendance at a urinary incontinence workshop for nursing staff to evaluate if this would reduce diaper usage. Forty-six percent of those surveyed attended the education workshop, and $98 \%$ of those reported utilizing behavioral therapy in the management of urinary incontinent patients. The majority of nursing staff reported care of incontinent patients as time consuming, frustrating, and stressful. Seventy-nine percent of the nursing staff stated that they used diapers and indwelling catheters for urinary incontinence. The researchers concluded that existing nursing practice would delay patients regaining urinary continence. Further they concluded equal distribution amongst the staff of the work assignments for urinary incontinent 
Evaluation of Urinary Incontinence Program

patients would help reduce staff stress and frustration.

Remsburg, Palmer, Langford, and Mendelson (1999) conducted a 12-week prompted voiding program with 17 residents of a long-term care facility. The study also evaluated the perception of the program by the nursing staff to see if their perceptions were similar to actual patient outcomes. Urinary incontinence episodes improved for five residents, urinary incontinence episodes remained the same for six residents, and urinary incontinence episodes increased for five residents. Ninety five percent of the nursing staff thought the patients were happier while on the prompted voiding program, and $52 \%$ of the staff thought the incontinent episodes had improved for residents. Forty-three per cent of the nursing staff perceived no change in the patients' incontinence status. The researchers concluded the nursing staff needed additional information on urinary incontinence and a better methodology for quantifying patient outcomes.

All of these studies suggested additional education for health care workers when dealing with urinary incontinent patients especially prior to beginning a behavioral therapy urinary continence program. It was most advantageous to design a research project utilizing a scheduled voiding program with incontinent stroke patients, in conjunction with an education program designed to assist health care workers with these patients.

\section{Conceptual Framework}

The conceptual framework for this research project utilizes Roy's adaptation theory. Roy (1984) defined health as "a state and a process of becoming integrated as a whole person" (p.28). Lack of integration represents lack of health. Roy believed an individual is 


\section{Evaluation of Urinary Incontinence Program}

an adaptive system which interacts with stimuli. The adjustment of an individual to a stressful situation or stimuli like urinary incontinence involves the use of resources in the physiological and psychosocial modes. Within the psychosocial modes are role function, self-concept, and interdependence which help classify the person's behavioral responses as either adaptive or ineffective (Pollack, 1993).

Urinary incontinence interrupts all three areas of the psychosocial mode. In the selfconcept mode, an individual's self-esteem is affected when urine leakage occurs, because by the age of three in normal growth and development urinary incontinence is accomplished. Many times a stroke patient suffers physical limitations that prohibit self-toileting and thus affect the interdependence mode. Role function can be affected by depression which is often associated with urinary incontinence (Rousseau \& Fuentevilla-Clifton, 1992).

The Roy model promotes the role of nursing and health promotion as an integral part of the patient's adaptation. The goal of nursing, according to Roy, is to promote the health of the system by using the nursing process to assess and support the system in achieving adaptation. As previously stated three of the four adaptation modes are affected by urinary incontinence. Thus the knowledgeable rehabilitation nurse, equipped with the treatment modalities for urinary incontinence, using a supportive attitude, encourages the incontinent stroke patient's adaptation.

\section{Research Question}

The research questions are:

1. Is there a difference in a patients' urinary continence after the initiation of the continence program comparing baseline continence logs to mid and discharge continence logs? 


\section{Evaluation of Urinary Incontinence Program}

2. Is there a difference in the patients' bladder sphincter control Functional Independence Measure (FIM) scores after the initiation of the continence program comparing baseline FIM scores to discharge FIM scores?

3. Is there a difference in the rehabilitation staffs' knowledge and attitudes regarding urinary incontinence before and after reviewing a teaching module about urinary incontinence?

\section{Methodology}

\section{Research Design}

This study used a quasi-experimental design to answer the research questions and determine the effects of the continence program. Scores to measure urinary incontinence were measured before and after the nursing intervention of a scheduled voiding program. Staff knowledge and attitudes were also measured before and after the scheduled voiding program.

\section{Setting and Sample}

The patient population of this study was a convenience sampling of patients with a baseline FIM score below 5 for sphincter control for bladder management and who had experienced at least one incontinent episode in a 24 hour time period. The FIM tool is used as a standard by rehabilitation units to classify patient conditions in order to evaluate the severity of rehabilitation patients disabilities and to provide a uniform data collection system (Bunch \& Dvonch, 1994). The majority of patients admitted to this 12-bed rehabilitation center in central California were patients recovering from a stroke who experienced urinary incontinence. For purposes of this study, urinary incontinence was considered to be any involuntary leakage of 
Evaluation of Urinary Incontinence Program

urine. Spinal cord injury patients were automatically eliminated from the study since the treatment of choice for them was intermittent self-catherization.

Procedure

Data Collection. Informed consent was obtained from each patient admitted to the scheduled voiding program. In addition an information packet contained: (a) general information on urinary incontinence, (b) urinary continence resources, and (c) the researcher's business card. A 20 minute video on urinary incontinence was also available for viewing. Within 72 hours of admission, a baseline assessment for sphincter control for bladder management was completed and used as the baseline FIM score. In conjunction with this, the 3 day voiding logs were also completed to identify the baseline incontinence episodes. The 24 hour continence log with the highest number of incontinent episodes was used as the admission incontinence baseline data.

\section{Program}

The continence program consisted of: (a) a signed informed consent form, (b) a patient and staff information packets, (c) the incontinence educational video, (d) a scheduled voiding routine every 3 hours during the day/every 4 hours during the night, (e) patient FIM scores for sphincter control for bladder management, (f) a 24-hour patient continence log for each patient during length of hospitalization, $(\mathrm{g})$ pre/post true and false knowledge test from the staff and (h) a staff attitude questionnaire from staff before and after the urinary incontinence program.

An every 3 hour scheduled voiding program was selected to accommodate the patients' rigorous schedule of therapies. If a patient requested to urinate prior to the designated 
Evaluation of Urinary Incontinence Program

voiding times and was unable to wait until that scheduled time, they were toileted at the requested time. If the patient's voiding request occurred within 60 minutes of the scheduled voiding, that voiding episode was considered part of the scheduled voiding routine. Patient requests to void outside of this 60 minute time frame were granted; however, the patient was toileted at the next designated time.

The rehabilitation staff members for the program $(\underline{N}=27)$ included: eight $\mathrm{RNs}$, two licensed vocational nurses, seven patient care technicians (PCTs), three physical therapists (PTs), four occupational therapists (OTs), two speech therapists (STs), and one physical therapy assistant. Each staff member met with the researcher individually for approximately 30 minutes prior to the onset of the program. During this time, the researcher administered the pretests, reviewed the urinary incontinence information packet. The information packet included: (a) background information, (b) assessment, (c) guidelines, (d) types of incontinence, (e) treatments, (f) management tips, (g) resources, and (h) definition of terms.

\section{Patient Measures}

The tools utilized for patients within this study were the FIM tool and the daily continence log. The FIM tool was designed to measure the severity of a patient's disability while recovering from illness on a rehabilitation unit (Bunch \& Dvonch, 1994). The FIM tool had six assessment sections: (a) self-care, (b) sphincter control, (c) mobility, (d) locomotion, (e) communication, and (f) social recognition. Each section had two to six subsections that were scored. The scoring of each subsection had seven levels of measurement indicated by numbers 1 through 7 . 
Evaluation of Urinary Incontinence Program

A score of 7 indicated complete independence, and a score of 6 indicated a modified independence utilizing a device to complete the activity. Scores of 3 to 5 indicated that caregiver assistance was needed. A score of 2 indicated maximum assistance was needed, and a score of 1 indicated total dependence. The FIM scores are considered a universal data collection format for medical rehabilitation (Bunch \& Dvonch, 1994).

The second patient measure was the continence log, which the rehabilitation staff kept on each patient each 24 hours during hospitalization. The continence log consisted of scheduled voiding times at $0700,1000,1300,1600,1900,2200$, and 0230 hours. The continence log had sections to identify and record (a) if the patient was wet or dry prior to urination-this section was not utilized, (b) the amount of urine voided, (c) post-void residual urine volume obtained by a bladder scanner, (d) the person who initiated the voiding request, and (e) the equipment used to complete urination. Record keeping of the incontinence logs was the responsibility of the patient care technicians (PCT's), RNs, OTs, PTs, and STs.

The rehabilitation staff who calculated the FIM scores were RNs, OTs, PTs, and STs. All rehabilitation staff were certified to complete FIM scores, and national certification was required every 2 years. Their most recent certification was completed in May of 1999. The staff had to achieve a predetermined reliability standard to receive this certification.

When a question occurred regarding the FIM score, the R.N. discussed the issue at shift report, reviewed the incontinence logs, and assigned a FIM score for the sphincter control for bladder management. At weekly staff conferences with the rehabilitation physician progress of 
Evaluation of Urinary Incontinence Program

the patients was discussed including the FIM scores.

\section{Staff Measures}

The tools utilized in this study to measure staff knowledge and attitudes were a true and false knowledge test and a staff attitude questionnnaire that utilize a Likkert scale. The true and false knowledge test was adapted from a workshop on "Incontinence in Older Person's" with permission from the Sepulveda Geriatric Research Education and Clinical Center (G.R.E.C.C.). The true and false knowledge test consisted of 15 questions related to urinary incontinence topics: (a) psychosocial issues, (b) types of treatment, (c) patient care interventions, and (d) general information. Each question was worth 1 point for a possible total of 15 points.

The staff attitude questionnaire consisted of 13 questions related to urinary incontinence:

(a) 4 questions about staff attitudes, (b) 3 questions about patient care interventions, (c) 4 questions about general information, and (d) 1 question about caregivers. Twelve of the questions utilized the Likert scale and one question was open ended asking staff what experiences they had found helpful in dealing with urinary incontinence. Each question utilized five choice options on the Likert scale with an assigned value: (a) always $=5$, (b) sometimes $=4$, (c) occasionally $=3$, (d) seldom $=2$, and (e) never $=1$. Each question was worth one point. The 4 attitude questions were written to elicit the choice of seldom or never as the optimal answer. The total possible points when measuring the sum of these 4 attitudinal questions was 4 . The content validity of the true and false knowledge test and the staff attitude questionnaire was evaluated by three urinary incontinence experts by this 
Evaluation of Urinary Incontinence Program

researcher. After all patients who participated in the urinary incontinence program had been discharged from the rehabilitation unit thus completing the study, the rehabilitation staff reviewed their information packets and were retested with both staff instruments. Data Analyses.

Overall pretest and posttest mean scores were compared on the true and false knowledge and the staff attitude tests. The four attitude questions on the staff attitude questionnaire were examined separately as well as overall. The pre and posttests of the four summed attitude questions became mean scores and were computed as mean scores and a dependent $t$ test was computed. Because each attitude question on the staff attitude questionnaire was evaluated individually a mean score could not be used since this variable had now become discreet. Therefore, the individual staff attitude questions were reported as a percentage of the staff who selected the optimal choice on the Likert scale. The true and false knowledge test questions were grouped into four incontinence topics. The pretest and posttest mean scores of each topic were compared. A dependent $\underline{t}$ test was then computed on each of these four topics. Descriptive statistics were used to summarize the scores and suggest changes to continence, independence, and the staff's knowledge and attitudes.

\section{Findings}

The ages of participants in this study $(\underline{N}=12)$ ranged from 16 to 87 years, with a median age of 67.5 . Five participants were male, and seven were female. Seven (58\%) of the participants were white and the 5 remaining (42\%) were Hispanic. Eight (66\%) of the 
Evaluation of Urinary Incontinence Program

participants had 5 to 8 medical diagnoses, with cerebral vascular accident being the primary diagnosis. The length of stay on the rehabilitation unit for these patients ranged from 9 to 30 days.

\section{Patient Independence Levels}

The baseline FIM mean score for 11 subjects was 1.91 out of a possible 7, which indicated total to maximum assistance was needed for bladder sphincter control when the study began. By the time of discharge, the FIM mean score was 5.55 which indicated minimal caregiver assistance was required or only standby assistance. Overall, the FIM mean score by time of discharge was markedly improved. One patient was omitted from this study because a Foley catheter was placed prior to discharge.

Patient Continence Levels

The median number of baseline incontinent episodes per 24 hours was 2.27 per patient. The median was reported because one patient, of these 11, skewed the baseline data with 10 incontinent episodes. The median score at length of stay was 1 incontinence episode; however, by the time of discharge, the median score was 0 . All but one patient had gained urinary continence by the time of discharge, and that was the patient who had the Foley inserted prior to discharge and this was his third admission to the rehabilitation unit with the diagnosis of stroke. This patient was excluded from the study.

\section{$\underline{\text { Staff Knowledge and Attitudes }}$}

Twenty-seven rehabilitation staff members participated in the urinary incontinence educational teaching module and testing: (a) 8 RNs, (b) 2 LVNs, (c) 7 PCTs, (d) 4 OTs, (e) 3 


\section{Evaluation of Urinary Incontinence Program}

PTs, (f) 1 PTA, and (g) 2 STs. The mean age of the rehabilitation staff members was 40.6. Five of the staff members were male and the remaining 22 were female. The educational levels for the staff varied from high school to graduate school.

The mean score on the true and false knowledge pretest was 10.85 out of a possible 15 points for all of the rehabilitation staff, and the posttest mean score was 11.59. The score improved almost a full point between the pretest and posttest $(0.74)$, however it did not reach statistical significance $(p=.06)$ On the item that stated continence logs were important in the treatment of urinary incontinence, 21 staff (77\%) agreed on the pretest and $27(100 \%)$ agreed on the posttest.

The true and false test knowledge questions were grouped into the following incontinence topics: (a) 3 questions about the treatment of incontinence, (b) 3 questions about psychosocial issues, (c) 3 questions about patient care interventions, and (d) 6 questions about general information. Each topic's overall pretest and posttest means were compared with dependent $t$ tests (Table 1). The pretest mean score for the treatment of incontinence was 2.7 out of a possible 3 points with a posttest mean score of 2.5 . The pretest mean score for psychosocial issues was 2.0 out of a possible 3 points with a posttest mean score of 2.2. The pretest mean score for patient care interventions was 2.2 out of a possible 3 points with a posttest score of 2.7 This difference was the only statistically significant difference $(p=.008)$. The pretest mean score for general information was 4.2 out of a possible 6 points with a posttest score of 4.1 .

The statistically significant result for the intervention topic was explained by the 
Evaluation of Urinary Incontinence Program

22

Table 1

Staff Knowledge $(\mathrm{N}=27)$

\begin{tabular}{llllll}
\hline Topic Possible score & Pretest mean & Posttest mean & Change & Correlation \\
\hline Treatment & 3 & 2.7 & 2.5 & -0.2 & $\mathrm{p}=.011$ \\
$\begin{array}{l}\text { Psychosocial } \\
\text { Patient Care }\end{array}$ & 2.0 & 2.2 & 0.2 & $\mathrm{p}=.11$ \\
Interventions & 3 & 2.2 & 2.7 & 0.5 & $\mathrm{p}=.008 *$ \\
General & & & & & \\
Information & 6 & 4.2 & 4.1 & -0.1 & $\mathrm{p}=.746$ \\
\end{tabular}

Note. * Statistically significant dependent $\underline{t}$ test. All other differences were not significant. 
Evaluation of Urinary Incontinence Program

improvement on two items regarding patient care interventions on which the optimal answers improved by six (22\%) and seven (26\%) staff members respectively, the largest improvement among the knowledge categories. These items relate to the use of incontinence logs and an inappropriate intervention with stress incontinence. The rehabilitation staff noted their incontinence log record maintenance as important in the treatment of urinary incontinence, and they also understood an inappropriate intervention which would not be helpful in the treatment of stress incontinence (ie. running to the bathroom would increase intrabdominal pressure causing stress incontinence). Thus the rehabilitation staff recognition of an inappropriate intervention with stress incontinence was an application of knowledge to clinical practice.

The results of the scores on the staff attitude questionnaire were somewhat less positive.

The attitude questions on the staff questionnaire were scored so that a lower posttest score represents a more postitive attitude, thus a higher pretest score and a lower posttest score are desired outcomes. A score of 20 represents the worst possible score while a score of 4 is the best possible score. The overall pretest mean score on the attitude questionnaire for the rehabilitation staff was 13.25 , and the posttest mean score was 13.77 , a slight decrease in attitude (0.52). A dependent $\underline{t}$ test on the staff attitude questionnaire overall pretest and postest mean scores was nonsignificant with a $\mathrm{p}$ value of .157 . When the overall pretest and posttest mean score was divided by four to give an approximation of the attitude for each item, values of 3.31 and 3.44 respectively were obtained, which ranked on the Likert scale between occasionally and sometimes. These were undesireable responses to the attitude questions.

The pre and posttests on each of the four attitude questions on the staff attitude urinary incontinence questionnaire were analyzed and the percentage of optimal responses 
Evaluation of Urinary Incontinence Program

was tabulated (Table 2). The format in which the attitude questions were written elicited a response of seldom or never as the optimal answers. The first attitude question stated, "I'm never quite sure what to do with incontinent patients," evaluating the comfort level of staff when caring for incontinent patients. Five (18\%) of the rehab staff scored optimally on the pretest score and six (22\%) scored optimally on the posttest, an increased comfort level in caring for incontinent patients by one person. The second attitude question stated, "I find with cognitively impaired patients it is much easier to put them in diapers and change them as needed," evaluating staff attitudes in the use of diapers for incontinent patients. Seven (26\%) of the rehab staff scored optimally on the pretest and four (15\%) scored optimally on the posttest, a decrease of 3 (10\%). The third attitude question stated, "It seems like immediately after the cognitively impaired incontinent patients are cleaned up they are incontinent again," evaluating staff attitudes about repetitively cleaning up after incontinent patients. Seven (26\%) of rehab staff scored optimally on the pre and posttests. The last attitude question stated, "I've tried various approaches to urinary incontinence with the cognitively impaired with the same results; nothing works," evaluates staff attitudes about approaches or techniques they have used with incontinent patients. Five (19\%) on the pretest believed their interventions worked and three (11\%) on the posttest believed their interventions worked, a decrease of two staff.

\section{Conclusion}

This study demonstrated that prior to discharge 11 of the 12 rehabilitation participants achieved urinary continence with the scheduled voiding program implemented on the rehabilitation unit. Both the FIM scores and number of incontinence episodes markedly 
Evaluation of Urinary Incontinence Program

Table 2

$\underline{\text { Staff Attitude }(\mathrm{N}=27)}$

Pretest

Frequency Percentage
Posttest

Frequency Percentage

Lack of comfort when

caring for incontinent

patients

5

$18 \%$

6

$22 \%$

Infrequent use of

diapers

7

$26 \%$

4

$15 \%$

Perception of repetitively

cleaning up incontinent

patients

7

$26 \%$

7

$26 \%$

Belief that nothing works

with incontinent patients

(staff interventions)

5

$19 \%$

3

$11 \%$

Note. Frequency indicates the number of staff who indicated the optimal answers of seldom or never on the Likert scale. 
Evaluation of Urinary Incontinence Program

improved with this program. This study supports the use of scheduled voiding to gain continence as a behavioral therapy intervention with bladder training.

This study was limited by: (a) sample size, (b) measurements of staff knowledge and attitudes, and (c) measurement of patient continence. The small nonrandomized sample size of this study may not be representative of a urinary incontinent population at large; therefore, generalizing the results of this study to another patient population is not possible. Although the content validity on the true and false knowledge test and the staff attitude questionnaire was evaluated psychometric properties were not available. Therefore these tests may not have captured a valid or reliable measure of staffs' knowledge and attitude; generalizing beyond this particular sample is not possible. Only one research study by $\mathrm{Yu}$ and Kaltreider (1987) utilized an incontinence Stress Questionnaire-Staff Reaction instrument which was tested for content analysis; however, tool reliability was unacceptable. The development of a reliable valid tool for the measurement of staff attitudes would be helpful for future researchers, allowing a standard by which to compare results. Only one researcher (Linn, 1995) used a quantitative measurement to check patients for wetness and dryness prior to toileting them.

The staff knowledge improved overall and in two topic categories, although the posttest results suggest only a one point increase in staff knowledge after the educational teaching module was presented. Previous researchers (Cheater, 1991; Freundal \& Dugan, 1992; Hancock, Bender, Dayhoff, \& Nyhuis, 1996) have identified health care workers as needing additional urinary incontinence education. This need is also supported by the results of this study since only a slight increase in staff knowledge was noted after the education teaching module. 
Evaluation of Urinary Incontinence Program

The attitudes of the rehabilitation staff did not increase overall and for 3 of 4 categories, was lower on the posttest results. Only one of the four questions on attitude showed an an increase in the number of staff who reported an optimal response (staffs' comfort level when caring for incontinent patients) and that improvement was by only one staff member. The educational teaching module had little effect on the attitudes of the rehabilitation staff. The study has practical implications for health care educators who need to include urinary incontinence information in the education of health care workers. It also has implications for staff educators within a rehabilitation setting to utilize a staff teaching module to orient new employees to patient care interventions used in the care of incontinent patients.

This study has relevant practical implications for rehabilitation centers in the use of scheduled voiding programs for gaining continence. The Roy adaptation theory is well suited for the rehabilitation environment. This model could help in the design of a rehabilitation unit's continence program by using the individual FIM scores to act as triggers in the selection of patient care strategies based on the Roy model to treat incontinent rehab patients. Within the rehabilitation unit the Roy model could provide a foundation for the continence intervention program. For example, identifying FIM score ranges that are most likely to succeed. Although in this study every rehabilitation patient improved, a larger sample size might identify FIM score ranges that could predict achievement for successful continence.

Further research studies need to be conducted with larger randomized patient samples, using patient continence evaluations at timed intervals (weeks or months) to observe whether continence continues post discharge. Although this staff teaching module did not change staff 
$\circlearrowleft \quad$ Evaluation of Urinary Incontinence Program

attitudes, future researchers could develop a longer and more formalized teaching module which might subsequently change staff attitudes. 
Evaluation of Urinary Incontinence Program

\section{References}

Appell, R. A., \& Baum, N. (1992). Evaluation of urinary incontinence in the elderly. Journal of the Louisana State Medical Society, 144, 517-521.

Brazier, J. \& Kramer J. (1999, June). Introduction to incontinence in older persons. Paper presented at the Sepulveda Geriatric Research Education and Clinical Center Conference on "Incontinence in Older Persons", Woodland Hills, CA.

Bunch, W. H., \& Dvonch, V. M. (1994). The value of functional independence measure scores. American Journal of Physical Medicine \& Rehabilitation, 73, 40-43.

Burgio, K. L., \& Goode, P. S. (1997). Behavioral interventions for incontinence in ambulatory geriatric patients. The American Journal of the Medical Sciences, 314, 257-261.

Burgio, K. L., Locher, J. L., Goode, P. S., Hardin, J. M., McDowell, B. J., Dombrowski, M., \& Candib, D. (1998). Behavioral vs. drug treatment for urge urinary incontinence in older woman. Journal of the American Medical Association, 280, 1995-2000.

Cheater, F. (1991). Attitudes towards urinary incontinence. Nursing Standard, 5, 23-27.

Connor, P. A., \& Kooker, B. M. (1996). Nurses' knowledge, attitudes, and practices in managing urinary incontinence in the acute care setting. MEDSURG Nursing, 5, 87-92.

Cummings, V., Holt, R., van der Sloot, C., Moore, K., \& Griffiths, D. (1995). Costs and management of urinary incontinence in long-term care. Journal of Wound, Ostomy, and Continence Nursing, 22, 193-198.

Fantl, J. A. (1998). Behavioral intervention for community-dwelling individuals with urinary incontinence. Urology, 51, 30-34. 
Evaluation of Urinary Incontinence Program

Fantl, J. A., Wyman, J. F., McClish, D. K., Harkins, S.W., Elswick, R. K., Taylor, J. R., \& Hadlesy, E. C. (1991). Efficacy of bladder training in older women with urinary incontinence. Journal of the American Medical Association, 265, 609-613.

Freundl, M., \& Dugan, J. (1992). Urinary incontinence in the elderly knowledge and attitude of long-term care staff. Geriatric Nursing, 13, 70-75.

Glasser, L. L., Zorowitz, R. D., \& Linsenmeyer, T. A. (1997). Continence status at rehabilitation admission poststroke does not predict 3 to 4 year institutionalization. Topics in Stroke Rehabilitation, 3, 38-50.

Hancock, R., Bender, P., Dayhoff, N., \& Nyhuis, A. (1996). Factors associated with nursing interventions to reduce incontinence in hospitalized older adults. Urologic Nursing, 16, 79-85.

$\mathrm{Hu}, \mathrm{T}$. (1990). Impact of urinary incontinence on health care costs. Journal of American Geriatrics Society, 38, 292-295.

Kamouchi, M., Ibayashi, S., Takaba, H., Omae, T., Sadoshima, S., Yamashita, Y., \& Fujishima, M. (1995). Urinary incontinence in elderly patients in the chronic stage of stroke. Japanese Journal of Geriatrics, 32, 741-746.

Linn, J. G., Best, H. L., \& Holzapfel, K. M. (1995). Behavioral treatment of urinary Incontinence. (http://www.vard.org/prog/95/ch05/pr95103.htm 3/23/00).

Medical Outcomes \& Guidelines Sourcebook, (1997 ed.). (1997). Washington, DC: Faulkner-Gray.

Messick, G. M., \& Powe, C.E. (1997). Applying Behavioral Research to Incontinence. Journal of Wound, Ostomy, and Continence Nursing, 43, 40-48. 
Evaluation of Urinary Incontinence Program

Mitteness, L. S. (1990). Knowledge and beliefs about urinary incontinence in adulthood and old age. Journal of American Geriatrics Society, 38, 374-378.

Ouslander, J. G., \& Schnelle, J. F. (1995). Incontinence in the nursing home. Annals of Internal Medicine, 122, 438-449.

Owen, D. C., Getz, P. A., \& Bulla, S. (1995). A comparison of characteristics of patients with completed stroke those who achieve continence and those who do not. Rehabilitation Nursing, 20, 197-203.

Penn, C., Lekan-Rutledge, D., Joers, A. M., Stolley, J. M., \& Amhof, N. V. (1996). Assessment of urinary incontinence. Journal of Geronatological Nursing, 22, 8-19.

Pollack, S. (1993). Adaptation to chronic illness: a program of research for testing nursing theory. Nursing Science Quarterly, 6, 86-92.

Publicover, C., \& Bear, M. (1997). The effect of bladder training on urinary incontinence in community-dwelling older women. Journal of Wound, Ostomy, and Continence Nursing, 24 , 319-324.

Remsburg, R. E., Palmer, M. H., Langford, A. M., \& Mendelson, G. F. (1999). Staff compliance with and ratings of effectiveness of a prompted voiding program in a long-term care facility. Journal of Wound, Ostomy, and Continence Nursing, 26, 261-269.

Resnick, N. M. (1995). Urinary Incontinence. The Lancet, 346, 94-99.

Rousseau, P., \& Fuentevilla-Clifton, A. (1992). Urinary incontinence in the aged Part 1: patient evaluation. Geriatrics, $47,22-48$.

Roy, C. (1984). Introduction to nursing an adaptation model. Englewood Cliffs, NJ: 
Evaluation of Urinary Incontinence Program

Prentice-Hall.

Tinetti, M. E., Inouye, S. K., Gill, T. M., \& Doucette, J. T. (1995). Journal of the American Medical Association, 273, 1348-1353.

U.S. Department of Health and Human Services. (1996). Urinary Incontinence in Adults Acute and Chronic Management (AHCPR Publication No. 96-0682). Rockville, MD: Fantl et al.

Wagner, T. H., \& Hu, T. (1998). Economic costs of urinary incontinence in 1995. Urology, $\underline{51,355-361 .}$

Ween, J. E., Alexancer, M. P., D’Esposito, M., \& Roberts, M. (1996). Neurology, 47, 659663.

Weinberger, M. W., Goodman, B. M., \& Carnes, M. (1999). Long-term efficacy of nonsurgical urinary incontinence treatment in elderly woman. Journal of Gerontology, 54A M117-M121.

Wyman, J. F., Fantl, J. A., McClish, D. K., Bump, R. C., \& the Continence Program for Women Research Group. (1998). Comparative efficacy of behavioral interventons in the management of female urinary incontinence. American Journal of Obstetric and Gynecology, 179. 999-1007.

Yu, L. C., \& Kaltreider, D. L. (1987). Stressed nurses dealing with incontinent patients. Journal of Gerontological Nursing, 13, 27-30. 